\section{¿Son inmunes a la hepatitis B los trabajadores de salud vacunados?}

Se recomienda que los trabajadores de la salud se vacunen contra la hepatitis $B$, que se transmite por la vía sanguínea. No obstante, la vacuna se asocia con una falta de respuesta en 5 a $32 \%$ de las personas vacunadas y no hay ningún protocolo uniformado para confirmar, vigilar o mantener la inmunidad en esas personas. En vista de esta situación, un grupo de investigadores sometió a examen serológico a 154 trabajadores de la salud que habían recibido la vacuna anti-hepatitis $B$ para determinar su estado inmunitario. Se hicieron determinaciones de antígeno de superficie (HBs) y antígeno nuclear $(\mathrm{HBc})$, así como determinaciones cuantitativas y cualitativas de anticuerpos anti-HBs. Mediante una encuesta de conveniencia también se recolectaron datos sobre la fecha de la vacunación, el número de dosis de vacuna, determinaciones previas de títulos de anticuerpos y sus resultados, sexo, ocupación y edad en el momento del estudio y de la vacunación.

Los resultados revelaron dos grupos: el grupo A $(n=109,71 \%)$ tuvo títulos de anticuerpos detectables; el grupo B $(n=45,29 \%)$ no tuvo anticuerpos detectables. El grupo A había recibido un promedio de 2,91 dosis (error estándar: $\pm 0,04$ ) de vacuna 4,8 años (error estándar: $\pm 0,3$ ) antes del estudio y sus títulos de anticuerpos eran, en promedio, de $112,91 \mathrm{mUI} / \mathrm{mL}$ (error estándar: $\pm 5,18$ ). No se observó ninguna diferencia estadísticamente significativa entre los grupos A y B en el tiempo transcurrido desde la vacunación, el número de dosis, el sexo, la ocupación o la edad en el momento del estudio y de la administración de la vacuna. De seis personas del grupo B que recibieron dosis de refuerzo, todas formaron anticuerpos anti-HBs. Solamente 62 personas $(40 \%)$ en toda la población estudiada habían sido sometidas a determinaciones previas de anticuerpos anti-HBs. De ellas, 48 (77\%) mostraron inmunidad al virus de la hepatitis $B$.

En este estudio, 29\% de los trabajadores de la salud que habían recibido la vacuna contra la hepatitis B no mostraron ninguna inmunidad detectable contra la enfermedad. No se sabe si se trata de individuos que nunca formaron anticuerpos, que los perdieron con el tiempo, o que aún conservaban la memoria inmunitaria. El hecho de que todas las personas que recibieron dosis de refuerzo hayan mostrado títulos de anticuerpos detectables parece indicar que poseían inmunidad. En vista de estos resultados, se recomienda 1) evaluar la inmunidad 1 a 2 meses después de la vacunación contra la hepatitis B para documentar si se ha producido una respuesta inmunitaria; 2 ) efectuar pruebas periódicas para la detección de anticuerpos anti-HBs; y 3) aplicar dosis de refuerzo a los trabajadores de la salud vacunados con el fin de que conserven títulos de anticuerpos lo suficientemente altos para mantenerse inmunes. (Barash C, Mitchell I, DiMarino AJ, Marzano J, Allen ML. Serologic hepatitis B immunity in vaccinated health care workers. Arch Int Med 1999;159:1481-1483.)

\section{Los medicamentos para prevenir la osteoporosis: ¿cómo elegirlos?}

El alendronato sódico y el clorhidrato de raloxifeno han sido aprobados para prevenir la osteoporosis en mujeres posmenopáusicas, pero aún no hay datos sobre su eficacia clínica. En un estudio reciente se compararon estos medicamentos con la terapia estrogénica de reemplazo (TER) a fin de ayudar a las mujeres y a los médicos que las atienden a escoger el mejor tratamiento. Se creó un modelo analítico decisorio de tipo markoviano con el propósito de comparar los efectos del tratamiento con alendronato, raloxifeno y TER sobre la esperanza de vida y sobre los riesgos de fractura de cadera, enfermedad coronaria y cáncer de mama. En los modelos de regresión se vincularon los factores de riesgo individuales con el riesgo de enfermedad futura y se observaron modificaciones según los efectos del medicamento en la densidad ósea, las concentraciones de lípidos séricos y efectos relacionados con el cáncer de mama.

Según los resultados predictivos, la TER, el alendronato y el raloxifeno tienen igual eficacia para prevenir las fracturas de cadera (riesgos relativos estimados: $0,57,0,54$ y 0,58 , respectivamente). La eficacia de la TER debería ser más de 10 veces mayor que la del raloxifeno en lo que respecta a la prevención de la enfermedad coronaria, pero este último medicamento no debería inducir el cáncer mamario. Las mujeres que tienen poco riesgo de fractura de cadera, enfermedad coronaria y cáncer de mama no obtienen ningún beneficio significativo con estos medicamentos. En mujeres con riesgo mo- 
derado se prefiere el tratamiento con TER, a no ser que en ellas el raloxifeno pueda reducir el riesgo de cáncer de mama en $66 \%$ o más, ya que el riesgo de esta enfermedad aumenta en $47 \%$ con la TER. Las mujeres cuyo riesgo de enfermedad coronaria es alto son las que más se benefician de la TER. Las que tienen un riesgo elevado de cáncer de mama pero poco riesgo de enfermedad coronaria se benefician más con el raloxifeno, pero únicamente si este les reduce el riesgo de cáncer mamario.

En resumen, las diferencias significativas en los efectos que producen estos medicamentos implican que la elección del tratamiento debe basarse en el riesgo individual de cada mujer de sufrir fractura de cadera, enfermedad coronaria y cáncer de mama. (Nananda F, Pauker SG, Goldberg RJ, Eckman $\mathrm{MH}$, Orr RK, Ross EM, et al. Individualizing therapy to prevent long-term consequences of estrogen deficiency in postmenopausal women. Arch Int Med 1999;159:1458-1466.)

\section{El citomegalovirus como facilitador de la progresión de la infección por VIH-1}

Se sabe desde hace mucho tiempo que el citomegalovirus (CMV) actúa como cofactor en la progresión de la infección por el virus de la inmunodeficiencia humana tipo 1 (VIH-1). En un estudio reciente se estudió prospectivamente a 440 lactantes (75 de ellos con infección por VIH-1 y 365 sin infección) con CMV que habían nacido de madres infectadas por VIH-1. Se definieron como indicadores de progresión de la infección por VIH-1 la presencia de síntomas de clase C (según los criterios de los Centros para el Control y la Prevención de Enfermedades en Atlanta, Georgia) o recuentos de linfocitos CD4 menores de 750 células por milímetro cúbico antes de cumplir 1 año y de menos de 500 células por milímetro cúbico antes de cumplir 18 meses.

Se observó una frecuencia similar de infección por CMV al nacer en los niños con y sin infección por VIH-1 (4,3 y 4,5\%, respectivamente). No obstante, los lactantes infectados por VIH-1 mostraron una mayor tasa de infección por CMV a los 6 meses de edad $(39,9$ frente a $15,4 \%, P=0,001)$ y siguieron teniéndola hasta que cumplieron 4 años de edad $(P=0,04)$. Al llegar a los 18 meses, los lactantes con ambas infecciones mostraron progresión de la infección por VIH-1, síntomas tipo C o muerte, así como déficits de la coordinación motora o anomalías del desarrollo cerebral con mayor frecuencia que los niños que solo tenían VIH-1. Se efectuó un análisis de regresión de Cox, el cual arrojó una asociación con un riesgo aumentado de progresión de la infección por VIH-1 (riesgo relativo, 2,59; IC95\%, 1,13 a 5,95).
Se concluye, sobre la base de los resultados obtenidos en este estudio, que los lactantes infectados por VIH-1 que contraen la infección por CMV durante los primeros 18 meses de vida muestran un aumento significativo de la progresión de la infección por VIH-1 y de afección del sistema nervioso central que los que solamente tienen infección por VIH-1. (Kovacs A, Schluchter M, Easley K, Demmler G, Shearer W, La Russa P, et al. Cytomegalovirus infection and HIV-1 disease progression in infants born to HIV-1 infected women. N Engl J Med 1999;341(2):77-84.

\section{Debate sobre el uso de tamoxifeno en mujeres en riesgo de cáncer de mama}

Un grupo de estudio convocado por el grupo más grande de expertos estadounidenses en materia de cáncer recomienda, con precaución, que los médicos contemplen la posibilidad de administrar tamoxifeno como tratamiento preventivo a mujeres mayores de 34 años con un riesgo aumentado de sufrir cáncer de mama. Esta recomendación, que se anunció públicamente durante la reunión anual de la Sociedad Estadounidense de Oncología Clínica (American Society of Clinical Oncology, ASCO), distó de ser una declaración entusiasta a favor del uso del medicamento en mujeres sanas. Más bien, se trató de una afirmación de que el tamoxifeno, medicamento que se liga con los receptores de estrógenos en los tejidos, debe ofrecerse de manera optativa a mujeres en riesgo de cáncer de mama para que ellas elijan si tomarlo o no sobre la base de la información a su alcance. Esta debe abarcar una evaluación y discusión de los factores de riesgo individuales, procurando sopesarlos contra los efectos adversos que puede producir el medicamento (un mayor riesgo de cáncer uterino, de trombosis mortales y de bochornos y otros síntomas de la menopausia). La decisión de cada mujer dependería, por lo tanto, de su riesgo verdadero de contraer cáncer de mama y de la importancia que ella le dé a ese riesgo.

El informe del grupo de estudio se basó en una revisión de la literatura publicado desde 1990 sobre el uso del tamoxifeno y del raloxifeno, cuyo mecanismo de acción es similar. Ambos medicamentos tienen actividad contra tumores que poseen receptores a estrógenos, pero no contra tumores que carecen de estos receptores. Aún no hay pruebas suficientes para justificar el uso de raloxifeno como medicamento preventivo contra el cáncer mamario. En una etapa futura del ensayo clínico prospectivo denominado STAR (Study of Tamoxifen and Raloxifen) se pondrá a prueba la hipótesis de que estos dos fáarmacos pueden prevenir el cáncer 
mamario. Este ensayo, que tiene el apoyo del Instituto Nacional de Cáncer (National Cancer Institute) de los Estados Unidos, está reclutando voluntarias mayores de 34 años en Canadá, Estados Unidos y Puerto Rico.

Por el momento, las mujeres con un riesgo aumentado de cáncer de mama no disponen de acceso a un tratamiento preventivo de eficacia confirmada. Los resultados del estudio STAR no se sabrán hasta dentro de varios años. Y si bien es cierto que los resultados obtenidos hasta el momento permiten recomendar el uso de tamoxifeno en mujeres en mayor riesgo, es necesario observar gran precaución a la hora de administrar el fármaco. La decisión de administrarlo debe hacerse como parte de un proceso decisorio entre médico y paciente en el cual deben sopesarse cuidadosamente el riesgo de contraer cáncer de mama, los beneficios que ofrece el medicamento, y las demás opciones. (Stephenson J. Experts debate drugs for healthy women with breast cancer risk. JAMA 1999;282:117-118.)

\section{Vacuna inhalable contra la influenza}

El virus de la influenza puede ocasionar un grave trastorno de salud en personas de cualquier edad. No solamente altera las actividades cotidianas de quienes se enferman, sino que también lleva a una sobrecarga de los servicios de atención sanitaria. Aunque cada año se elaboran vacunas contra la enfermedad, su aplicación suele recomendarse solamente en personas de edad avanzada, quienes son más susceptibles a la neumonía y a otras complicaciones. En un estudio reciente se examinó la eficacia e inocuidad de una vacuna trivalente intranasal elaborada a base de virus vivos atenuados. Se prestó especial atención a la reducción de los síntomas, del absentismo y del uso de servicios de salud en personas adultas pertenecientes a la fuerza de trabajo. El ensayo se efectuó a doble ciego con una muestra aleatoria de 4561 adultos sanos entre las edades de 18 y 64 años suscritos a 13 centros de salud de los Estados Unidos. Un grupo recibió la vacuna trivalente intranasal y el otro, placebo.

Las principales variables de resultados fueron los episodios de enfermedad febril, grave o moderada; síntomas del árbol respiratorio superior, con fiebre; ausencia del trabajo; uso de servicios de salud durante la estación en que la influenza alcanza su máxima frecuencia; y un desenlace negativo. Como era de esperar, las personas vacunadas tuvieron uno o más episodios febriles durante épocas de brote, al igual que las no vacunadas. No obstante, la vacunación redujo de manera significativa el número de episodios febriles graves (en 18,8\%; IC95\%: 7,4 a 28,8\%) y de enfermedades febriles del árbol respiratorio superior (en 23,6\%; IC95\%: 12,7 a $33,2 \%$ ). La vacuna también redujo el número de días de enfermedad de toda clase (en $22,9 \%$ las enfermedades febriles; en 27,3\% las enfermedades febriles graves) y llevó a menos días de ausencia del trabajo (reducción de 17,9\% en el caso de enfermedades febriles graves y de $28,4,9 \%$ en el de enfermedades respiratorias superiores) y a menos visitas a proveedores de atención de salud (reducción de $24,8 \%$ por enfermedades febriles graves y de $40,9 \%$ por enfermedades respiratorias superiores con fiebre). También se redujo la prescripción de antibióticos y de medicamentos dispensados sin receta para tratar los diferentes síndromes. Aunque las personas vacunadas se vieron más afectadas por síntomas catarrales leves, como rinorrea o faringitis, en los primeros 7 días después de la vacunación, no se observó ninguna diferencia significativa entre los dos grupos en la frecuencia de desenlaces negativos. Fue pobre la coincidencia entre la cepa vírica usada en la vacuna $[\mathrm{A}(\mathrm{H} 3 \mathrm{~N} 2)]$ y la principal cepa vírica circulante (A/Sydney/05/97[H3N2]) durante la estación de 1997-1998, lo cual indica que la vacuna trivalente intranasal confirió bastante protección cruzada contra esta variante del virus de la influenza tipo A. En general, la vacuna se mostró inocua y eficaz en personas adultas pertenecientes a la fuerza laboral durante un año en que hubo predominio de una cepa vírica errante. (Nichol KL, Mendelman PM, Mallon KP, Jackson LA, Gorse GJ, Belshe RB, et al. Effectiveness of live, attenuated intranasal influenza virus vaccine in healthy, working adults: a randomized controlled clinical trial. JAMA 1999;282:137-144.)

\section{La vacuna combinada contra el VIH provoca distintas respuestas inmunes}

Según un análisis preliminar de los resultados de un estudio en que se administraron juntas dos vacunas distintas contra el virus de la inmunodeficiencia humana (VIH), la combinación es inocua y puede estimular diversas respuestas inmunes contra el virus. Se trata de la segunda fase de un ensayo clínico, el más grande que se haya efectuado hasta ahora, en 14 localidades de los Estados Unidos bajo el patrocinio del Instituto Nacional de Alergias y Enfermedades Infecciosas (National Institute of Allergy and Infectious Diseases, NIAID).

Una de las vacunas, la denominada ALVACHIV vCP205, estimula la inmunidad celular y produce células citotóxicas que pueden matar a las 
células infectadas por virus. La otra vacuna, que se denomina SF-2 rgp120, estimula la producción de anticuerpos neutralizantes contra VIH, que pueden impedir que los virus penetren en las células. Estas vacunas contienen solamente determinados componentes genéticos o proteínicos de VIH, y no el virus entero, de manera que una persona no puede infectarse por haberse vacunado.

El ensayo clínico, que se inició en mayo de 1997, se basa en una muestra de 435 hombres y mujeres sin infección por VIH. Los principales objetivos del estudio consisten en evaluar la capacidad inmunógena e inocuidad de la vacuna combinada en personas en riesgo de contraer VIH. Por consiguiente, más de $80 \%$ de los participantes tenían antecedentes recientes de uso de drogas inyectables o de prácticas sexuales de alto riesgo.

Los participantes fueron divididos en tres grupos aleatoriamente. El primero recibió ambas vacunas; el segundo, la vacuna vCP205 y placebo; y el tercero, dos placebos. Los voluntarios recibieron cuatro dosis en espacio de 6 meses; en cada ocasión, se les puso una inyección en cada brazo. Hubo algunos efectos secundarios leves con ambas vacunas, que se consideran inocuas sobre la base de lo observado hasta el momento.

En la mayor parte de los voluntarios, las vacunas han provocado respuestas inmunitarias contra VIH. Más de la mitad de las personas que recibieron solamente la vacuna vCP205, y más de $90 \%$ de las que recibieron ambas vacunas en combinación, han formado anticuerpos capaces de inhibir el VIH en pruebas de laboratorio. Cerca de una tercera parte de las personas que recibieron la vacuna vCP205 sola o en combinación han montado una respuesta celular con células citotóxicas. Si bien estos resultados son alentadores, el objetivo del estudio no ha sido determinar si la vacuna combinada tiene o no eficacia contra la infección por VIH o el sida.

La vacuna vCP205 (Pasteur Merieux Connaught, Lyon, Francia) consiste en una cepa vírica atenuada que contiene solamente algunos genes específicos de VIH. Este virus no puede crecer ni causar enfermedad en seres humanos y su virulencia se manifiesta principalmente en canarios. La vacuna SF-2 rgp 120 (Chiron, Emeryville, California, E.U.A.) es una copia de la proteína de superficie gp120 del VIH que ha sido obtenida por manipulación genética. Otras vacunas, también a base de virus procedentes de canarios, están en estudio actualmente. Por ahora, los datos necesarios para proseguir a la siguiente fase del ensayo clínico se esperan para fines del año 2000. (National Institute of Allergy and Infectious Diseases. Combination HIV vaccine induces diverse immune responses. Comunicado de prensa, 13 de julio de 1999.)

\section{Vacuna contra el cáncer cervicouterino en elaboración}

En febrero de 1999 se celebró en la sede de la OMS en Ginebra una reunión con objeto de evaluar el estado actual de varias vacunas profilácticas que se están elaborando para evitar la infección por el papilomavirus humano (PVH). La vacuna que resulte eficaz será solo la segunda que hasta el momento se haya elaborado con miras a prevenir un cáncer de mucha importancia para la salud pública. La primera fue la vacuna contra la hepatitis B, que previene el cáncer primario del hígado. Con esta segunda vacuna se espera reducir la incidencia del cáncer cervicouterino, el segundo en importancia para las mujeres después del cáncer de mama. El cáncer cervicouterino es una enfermedad de transmisión sexual causada por el PVH, cuya infección se suele adquirir en los primeros años de actividad sexual. Sin embargo, se tarda hasta 20 años en desarrollarse y convertirse en un tumor maligno. La función del PVH en el desarrollo de cáncer no se descubrió hasta 1983. Anualmente se detectan por lo menos 500000 casos de cáncer cervicouterino y la mortalidad resultante es sumamente alta. De ese número sucumben alrededor de 300000 mujeres, $80 \%$ de ellas en países en desarrollo. Hay una enorme discrepancia entre la incidencia del cáncer cervicouterino en esos países y la que se registra en las naciones industrializadas, lo que se debe en gran parte a la mayor oportunidad de tamizaje y detección de la enfermedad en estas. La proporción de cánceres atribuible al PVH oscila entre 3 y $5 \%$ en Norteamérica y Europa occidental, pero llega de 20 a $24 \%$ en América Latina, el sudoeste de Asia y África subsahariana.

Las vacunas en desarrollo se basan principalmente en partículas similares al PVH compuestas por ingeniería genética de las proteínas estructurales externas del virus. Las partículas no son infecciosas ni cancerígenas porque carecen de ADN. Algunas vacunas se están elaborando con fines profilácticos, mientras que otras tienen fines terapéuticos y se emplearían en mujeres que ya han adquirido la infección. En otras se están tratando de combinar los dos propósitos. Los obstáculos más graves con que se tropieza en esta empresa son que el PVH no puede replicarse en cultivos ni transmitirse a otros animales $y$, además, que la experimentación en seres humanos está limitada por el carácter cancerígeno de los virus naturales. No obstante, la similitud en la organización genética de todos los papilomavirus permite observar modelos animales que contribuyen a entender la interacción entre el virus humano y el huésped. Esas observaciones y los ensayos de primera fase indican que las vacunas 
profilácticas pueden llegar a bloquear el desarrollo del cáncer cervicouterino.

En la reunión llevada a cabo en febrero, hubo consenso de que la vacuna profiláctica debe tener prioridad en función de la salud pública, si bien la vacuna terapéutica tendría también utilidad considerable. La vacuna profiláctica se aplicaría preferentemente a la población joven que todavía no ha iniciado su actividad sexual. Por la diversidad de poblaciones en riesgo, es esencial que en los ensayos se incluyan muestras representativas de la comunidad mundial. Actualmente es aún muy temprano para decidirse por una vacuna en particular y la OMS apoya la evaluación mediante el ensayo de distintas versiones. La Organización establecerá los criterios para evaluar los resultados y patrocinará a grupos que realicen estudios epidemiológicos y económicos con el fin de implementar los ensayos de las vacunas y por último seleccionar la más idónea para uso público. (Organización Mundial de la Salud. First cervical cancer vaccine-from pipe dream to pipeline. Comunicado de prensa, 19 de febrero de 1999.)

\section{Diferencias culturales en lo que se interpreta como maltrato}

El maltrato de las esposas y esposos es un rasgo universal de las sociedades humanas y se ha documentado a lo largo de toda la historia. El código de leyes más antiguas, el de Hammurabi, les daba a los hombres el derecho de castigar a sus esposas. Este tipo de maltrato tiene manifestaciones físicas, verbales, psicológicas, emocionales, sexuales y económicas. Hay quienes han tratado de mostrar que las mujeres no son víctimas con mayor frecuencia que los hombres, pero muchos otros estudios repudian esa opinión. Lo que sí está claro es que se trata de un fenómeno sumamente complejo y que nadie puede explicar por qué ocurre, por qué se tolera ni por qué se perpetúa. Aparte de las sanciones sociales a favor o en contra de la violencia, hay muchas variables culturales que afectan a la incidencia del maltrato de la mujer en particular. En una cultura patriarcal se considera que los hombres deben ser dominantes, insensibles, duros y agresivos y se les castiga si muestran las características opuestas. Además, en esa sociedad se estima al hombre que es hábil en el uso de la agresión para resolver problemas. En virtud de todo ello, el hombre tiene el derecho y la obligación de controlar a su esposa, incluso por la violencia. Por el contrario, en las sociedades donde las mujeres tienen un poder considerable fuera del hogar, ya sea de índole económica o religiosa, se manifiesta menos el maltrato de la mujer, si bien ello no es cierto en todas las so- ciedades. También se relacionan con la violencia contra la mujer en general los celos sexuales de los hombres que la consideran propiedad suya. La información obtenida de otras culturas indica que donde hay pocos celos hay poco maltrato de la esposa y vice versa. En donde se cultiva la pasividad de la mujer, como en Taiwán, Ecuador, Irán y la India, se toleran diferentes grados de abuso. No obstante, aun en sociedades donde la mujer no se considera pasiva el maltrato físco de la mujer puede llegar a extremos espantosos. Es decir, que la ausencia de pasividad femenina se asocia con menos violencia mutua, pero no necesariamente con menos maltrato. Hay pocos estudios multiculturales sobre este tema. Un estudio reciente abordó la posibilidad de que la percepción del maltrato entre esposos y las implicaciones legales para quienes asesinan a quienes los maltratan estén regidas por patrones culturales. Los 58 participantes estudiaban en universidades de los Estados Unidos de América: 10 varones y 10 mujeres de América Latina (Argentina, Brasil, Chile, Colombia y Venezuela) y otro tanto de los Estados Unidos (región nordeste), y 10 mujeres y 8 varones de países asiáticos. Las medianas de edad de los grupos fueron, respectivamente, 21,3 años, 23,4 años y 21,7 años. Se les administró un cuestionario de 23 preguntas. Los análisis de la varianza mostraron diferencias estadísticamente significativas en siete de las preguntas, pero no en las 16 restantes.

Una de las diferencias más marcadas se observó en respuesta a una pregunta sobre la salud mental del perpetrador y la víctima. La mayoría de los latinoamericanos opinaron que ambos tienen problemas de salud mental. Otra fue la opinión de los asiáticos de que puede justificarse que un hombre le pegue a su mujer. Los hombres latinoamericanos fueron el segundo grupo más de acuerdo con esa idea, pero las mujeres latinoamericanas no estuvieron de acuerdo con ello a pesar de que las asiáticas sí lo estuvieron. Los comportamientos de desquite o venganza revelaron diferencias entre los sexos. Las mujeres estuvieron más de acuerdo que los hombres en justificar que una mujer mate o mutile al marido o compañero que la haya maltratado intensa y frecuentemente. La mayor brecha entre los sexos se observó en los estadounidenses, con las mujeres mucho más a favor del comportamiento vengativo que los hombres. En el caso contrario de la mutilación de una mujer abusadora por su compañero, se notó una gran diferencia cultural en la aceptación de los asiáticos, pero no de los estadounidenses ni latinoamericanos. Los hombres asiáticos y las mujeres latinoamericanas coincidieron en que se justifica pegarle a una mujer que maltrata verbalmente al compañero. En cuanto a 
cuestiones de defensa legal, los latinoamericanos (y las mujeres de todos los grupos) mostraron la más alta aceptación de la noción de defensa propia en casos de asesinato del perpetrador. En esos casos, los latinoamericanos aprobaron también la defensa legal de locura temporaria, lo que coincide con su opinión de que la víctima que acepta el maltrato tiene algún trastorno mental.

En vista de las diferencias, el estudio sugiere que la incidencia, la tolerancia y la perpetuación del maltrato del compañero son fenómenos culturales. Ello implica que algunos grupos acepten el maltrato por ser menos conscientes de las alternativas. En cualquier marco de referencia, el comportamiento abusivo solo puede reducirse mediante la concienciación de que es inaceptable y no tiene que tolerarse. (Gabler M, Stern SE, Miserandino M. Latin American, Asian, and American cultural differences in perceptions of spousal abuse. Psychol Rep 1998;83:587-592).

\section{Sexagésimo Quinta Asamblea Científica Internacional del Colegio Estadounidense de Médicos Torácicos (American College of Chest Physicians)}

Fechas: $\quad 31$ de octubre al 4 de noviembre de 1999

Lugar: $\quad$ Chicago, Illinois, Estados Unidos

Tema: $\quad$ What can we do different to make a difference?

El Colegio Estadounidense de Médicos Torácicos, que publica la revista CHEST, anuncia su sexagésimo quinta reunión anual, donde se celebrarán sesiones didácticas sobre el manejo de enfermedades pulmonares y sobre la atención del paciente en estado crítico. La sesión plenaria tendrá la participación por satélite de C. Everett Koop, ex Director General de Salud Pública de los Estados Unidos de América, quien dará la charla de apertura y contestará preguntas acerca de los temas más debatidos actualmente en el campo de la medicina. Habrá dos simposios satélite sobre temas diversos y el último día se ofrecerán cursos intensivos de preparación para el Pulmonary Board Examination y el Critical Care Medicine Board Examination.

Información:

The American College of Chest Physicians

Member Services

3300 Dundee Road

Northbrook, Illinois, E.U.A.

Teléfono: 847-498-1400 ó 1-800-343-2227

Fax: $847-498-5460$

Internet: www.chestnet.org 